\title{
Clinical implications of plasma Nogo-A levels in patients with coronary heart disease
}

\author{
Yu Ding, Bei-Bei Gao, Liang Zhou, Xian-Hua Ye, Hong Li, Lei Lai, Jin-Yu Huang
}

Hangzhou First People’s Hospital, Nanjing Medical University, Hangzhou, China

Submitted: 11 November 2015

Accepted: 28 December 2015

Arch Med Sci 2017; 13, 4: 771-777

DOI: https://doi.org/10.5114/aoms.2016.58713

Copyright $\odot 2016$ Termedia \& Banach

\section{Abstract}

Introduction: Nogo-A is an important neurite growth-regulatory protein in the adult and developing nervous system. Recently, increasing evidence has shown that Nogo-A plays important roles in cardiac development and may act as a potential indicator for heart failure. In addition, increased oxidative stress has been found in individuals with cardiovascular diseases. However, not much is known regarding the expression levels of Nogo-A and reactive oxygen species (ROS) in patients with coronary heart disease (CHD). Therefore, we sought to investigate the relationship between Nogo-A, ROS levels and CHD.

Material and methods: The plasma Nogo-A and ROS concentrations of 122 acute coronary syndrome (ACS), 101 unstable angina pectoris (UAP), and 21 acute myocardial infarction (AMI) patients and 56 healthy controls were measured by enzyme-linked immunosorbent assay (ELISA). We further generated a receiver operating characteristic (ROC) curve to assess the diagnostic accuracy of Nogo-A and ROS in CHD.

Results: The Nogo-A and ROS levels were significantly higher in patients with CHD than those in healthy controls. In addition, multivariate logistic regression analysis revealed that the level of Nogo-A (odds ratio $(\mathrm{OR})=$ $1.624,95 \%$ confidence interval: $1.125-2.293, p=0.009$ ) is a risk factor for prediction of CHD. Nogo-A has diagnostic value, with an optimal threshold of $5.466 \mathrm{ng} / \mathrm{ml}$ for maximized diagnostic performance (59\% sensitivity and $78.6 \%$ specificity, area under curve, $p<0.05)$. However, ROS concentration is not a risk factor for prediction of $\mathrm{CHD}(\mathrm{OR}=0.999,95 \%$ confidence interval: $0.997-1.001, p=0.320$ ).

Conclusions: Increased plasma Nogo-A level may be associated with CHD.

Key words: Nogo-A, reactive oxygen species, coronary heart disease, oxidative stress.

\section{Introduction}

Cardiovascular diseases are the number one cause of death globally. Among these, coronary heart disease (CHD) is responsible for more than half of all cardiovascular events in individuals less than 75 years age. The prevalence of CHD is estimated to be $6.4 \%$ in US adults aged 20 years or older, which represents approximately 15.4 million Americans [1]. Despite the numerous studies, the pathophysiology of CHD remains largely unknown. Most recently, a growing body of evidence has shown that oxidative stress and the inflammatory response play important roles in the development of $\mathrm{CHD}$ [2-4]. Higher levels of reactive oxygen species (ROS) are often observed with microvascular pathology in CHD.

\author{
Corresponding author: \\ Jin-Yu Huang \\ Hangzhou First \\ People's Hospital \\ Nanjing Medical University \\ Huansha Road 261\# \\ 310006 Hangzhou, China \\ Phone: +86-15267086912 \\ E-mail: hjyu41@sohu.com
}


Excessive ROS production represents endothelial and smooth muscle dysfunction, resulting in oxidative stress-induced signaling activation and mitochondrial-mediated cell apoptosis, which leads to the progress of $\mathrm{CHD}[5,6]$. Therefore, therapeutic strategies are needed that target the oxidative damage and the downstream consequences such as apoptosis [7].

For this purpose, researchers from Jin's laboratory first identified a novel role for the amino-Nogo-A against oxidative stress and proposed a mechanism of the amino-Nogo-A-mediated signal-transduction pathway of scavenging ROS [8]. Nogo-A is a high-molecular-weight membrane protein mostly expressed in the central nervous system (CNS), oligodendrocytes and subsets of neurons [9]. Inhibition of Nogo-A can enhance axonal sprouting and help neurological recovery in a rodent model of ischemic injury [10]. In addition to being highly expressed in the brain and spinal cord, Nogo-A is clearly detectable in other tissues, including the heart, where its function remains largely unclear despite evidence that it may play a role in normal cardiac development [11, 12]. Knockdown of Nogo-A in cardiomyocytes is found to significantly inhibit hypoxia/reoxygenation-induced activation of the intrinsic pathway of apoptosis [13]. Moreover, Nogo-A has been reported to be a potential indicator of heart failure due to its evaluated expression in genetic models of dilated cardiomyopathy (DCM) and its increased mRNA expression in end-stage heart failure in humans [14]. However, to date, the correlation between Nogo-A and CHD is still uncharacterized.

Most recently, we investigated the plasma Nogo-B concentrations in patients with acute coronary syndrome (ACS) and unstable angina pectoris (UAP) [15]. We found that Nogo-B levels were significantly higher in patients with ACS and UAP when compared with healthy controls. Moreover, based on analysis of the receiver operating characteristic (ROC) curves, plasma Nogo-B may have diagnostic values for cardiovascular diseases. Therefore, we proposed that Nogo-B may serve as a risk factor for prediction of the development of severe coronary stenosis. In this study, to further understand the roles of Nogo-A and oxidative stress in CHD, we performed a case-control study to analyze the change of Nogo-A and ROS levels in $\mathrm{CHD}$. We also assessed the relation between these parameters and CHD.

\section{Material and methods}

\section{Study population}

Between June 2013 and June 2015, a total 122 patients with ACS, 101 patients with UAP and 21 patients with acute myocardial infarction (AMI) were admitted to the Department of Cardiology, Hangzhou First People's Hospital. Exclusion criteria were ongoing maintenance dialysis, a grave acute infectious disease, neoplastic disease, severe liver dysfunction, major surgery, a chronic inflammatory disease, and systemic lupus erythematosus (SLE). Patients who suffered severe life-threatening injury to other organs were also excluded. Moreover, 56 healthy age- and gender-matched controls were recruited in this study. The study protocol and informed consent approach were approved by the Ethics Committee of Hangzhou First People's Hospital before implementation. The study individuals or their relatives provided written informed consent to participate in this trial.

\section{Clinical and laboratory assessment}

Detailed demographics, anthropometrics, vital parameters, medical history, drug administration, medication and pedigree information were recorded for each participant through personal interviews. Blood pressure (BP) was measured by a sphygmomanometer. Body mass index (BMI) was calculated as the body weight $(\mathrm{kg})$ divided by the square of the height $\left(\mathrm{m}^{2}\right)$.

Serum triacylglycerol (TG), total cholesterol (TC), low-density lipoprotein (LDL), high-density lipoprotein $(\mathrm{HDL})$ and kidney function parameters were determined using routine automated assay methods following an overnight fast (Hitachi, Tokyo, Japan). Glycated hemoglobin $\mathrm{A}_{1 \mathrm{c}}\left(\mathrm{HbA}_{1 \mathrm{c}}\right)$ was detected by high-pressure liquid chromatography (HPLC) (Variant II; Bio-Rad, Hercules, CA, USA). Serum C-reactive protein (CRP) was measured by particle-enhanced immunonephelometry assay (Dade Behring Inc., NJ, USA). In addition, we measured the estimated glomerular filtration rate $(\mathrm{eGFR}) ; \mathrm{eGFR}=175 \times(\mathrm{Scr})^{-1.154} \times(\text { age })^{-0.203}[14]$.

\section{Diagnosis of ACS, UAP and AMI}

Coronary arteriography was carried out using the standard Judkins technique [16], and all major coronary arteries were examined in at least two orthogonal views. The arteriographic analysis was conducted by two experienced interventional cardiologists, who were blinded to the study's objective and design. Acute coronary syndrome was diagnosed according to the Guidelines of the American College of Cardiology (ACC) and American Heart Association (AHA) [17]; it was defined as either unstable angina or acute myocardial infarction, confirmed by electrocardiographic changes (ST-segment and T-wave changes) and cardiac enzyme. Unstable angina pectoris (UAP) was diagnosed in 101 patients, based on clinical symptoms, namely typical precordial chest pain of class IIB or IIIB in the Braunwald classification, angio- 
graphic evidence (documented severe stenosis of $75 \%$ according to the AHA classification in one or more major coronary artery), and changes in serum creatine kinase (CK) concentrations (no significant evidence of increase) [18]. The diagnosis of AMI was based on clinical symptoms, ST segment elevation (STEMI) on the electrocardiogram with non-ST segment elevation acute myocardial infarction (NSTEMI), coronary angiographic findings (occlusion of main coronary artery branch with thrombolysis in myocardial infarction (TIMI) grade flow of 0,1 , or 2 ), and changes in serum CK concentrations (more than two-fold increase from the upper limit of the normal range) [19].

\section{Determination of Nogo-A and ROS levels in plasma}

The blood samples were immediately placed into sterile ethylenediaminetetraacetic acid test tubes and centrifuged at $1500 \mathrm{~g}$ for $20 \mathrm{~min}$ at $4^{\circ} \mathrm{C}$ to collect plasma. Plasma was stored at $-70^{\circ} \mathrm{C}$ until assayed. The concentrations of Nogo-A and ROS in plasma were analyzed by ELISA using commercial kits (Nova Biomedical, MA, USA), in accordance with the manufacturer's instructions.

\section{Statistical analysis}

The SPSS software suite, version 19.0, was used for all statistical analyses (SPSS Inc., Chicago, IL). Normally distributed data were expressed as mean \pm standard deviation. For comparison of the continuous variables among patients with CHD and the control group, a standard one-way analysis of variance (ANOVA) test and Student's $t$-test were performed. The differences in the distribution of categorical variables were compared using the $\chi^{2}$ test. Initially, baseline variables were evaluated for univariate association with clinical outcome. Variables that were significant in univariate analyses were included in a multivariate logistic regression model to determine the risk-adjusted predictors of clinical outcome with odds ratio (OR) and $95 \%$ confidence interval $(\mathrm{Cl})$. Cut-off points for Nogo-A and ROS were determined to predict clinical outcome using ROC curves. The area under the curve (AUC) was calculated based on the ROC curves. An AUC closer to 1 indicated a higher predictive power. We considered a $p$-value less than 0.05 as significant for all tests.

\section{Results}

\section{Patients' characteristics}

This study eventually included 244 CHD patients including 122 ACS patients, 101 UAP patients and 21 AMI patients. Table I summarizes the demographic, clinical and biochemical data from these patients. The control group consisted of 56 age- and gender-matched healthy individuals. Among these parameters, TG, TC, HDL-C, LDL-C, $\mathrm{SCr}$ and hsCRP differed statistically significantly when compared with the healthy control group.

\section{Comparison of Nogo-A and ROS levels among ACS, UAP and AMI groups}

As shown in Table I and Figure 1, the serum concentrations of Nogo-A were significantly higher in patients with ACS, UAP and AMI $(6.95 \pm 3.66$; $6.93 \pm 3.72$ and $7.05 \pm 3.43 \mathrm{ng} / \mathrm{ml})$ than in control subjects $(4.16 \pm 2.48 \mathrm{ng} / \mathrm{ml})(p<0.001 ; p<0.001$; $p=0.001$, respectively).

Moreover, as shown in Figure 2, the plasma concentrations of ROS were higher in patients with ACS, UAP and AMI (991.82 \pm 773.38 ; 936.42 \pm 790.35 and $1258.25 \pm 636.66 \mathrm{lU} / \mathrm{ml})$ than in the control group $(580.64 \pm 369.87 \mathrm{IU} / \mathrm{ml})(p<0.001$; $p=0.002 ; p<0.001$, respectively).

\section{Diagnostic value of plasma Nogo-A for patients with CHD}

The ROC curve identified the cutoff values of plasma Nogo-A concentrations that predict the CHD patients with high sensitivity and specificity values (Figure 3 ). The results indicate that Nogo-A has diagnostic value, with an optimal threshold of $5.466 \mathrm{ng} / \mathrm{ml}$ for maximized diagnostic performance $(59 \%$ sensitivity and $78.6 \%$ specificity).

\section{Predictive value of increased Nogo-A concentrations for CHD}

We then calculated the OR and $95 \% \mathrm{Cl}$ using multiple logistic regression analysis to evaluate predictors of $\mathrm{CHD}$ for the entire study population (Table II).

Among these parameters, BMI $(\mathrm{OR}=1.666$, 95\% Cl: 1.294-2.145, $p=0.001)$, LDL-C (OR = 3.544, 95\% Cl: 1.420-8.848, $p=0.007)$, hsCRP $(\mathrm{OR}=1.225,95 \% \mathrm{Cl}: 1.046-1.436, p=0.012)$ and Nogo-A (OR = 1.624, 95\% Cl: $1.125-2.293$, $p=0.009)$ are predictive in the univariate analysis for CHD patients.

\section{Discussion}

The following are the major findings of the present study: 1) serum Nogo-A levels are higher in the CHD groups than in the control group; 2) serum ROS concentrations are higher in the CHD group than in the control subjects, indicating that oxidative stress may play a role in the pathogenesis of CHD; 3) plasma Nogo-A concentrations emerge as an independent predictor for CHD in a multivariate logistic regression model, with $59 \%$ 
Table I. Clinical and biochemical characteristics of patients with CHD

\begin{tabular}{|c|c|c|c|c|c|c|c|}
\hline Variable & $\begin{array}{c}\text { ACS } \\
(n=122)\end{array}$ & $P$-value & $\begin{array}{c}\text { UAP } \\
(n=101)\end{array}$ & $P$-value & $\begin{array}{c}\text { AMI } \\
(n=21)\end{array}$ & $P$-value & $\begin{array}{l}\text { Control } \\
(n=56)\end{array}$ \\
\hline $\begin{array}{l}\text { Gender (male), } \\
n(\%)\end{array}$ & $80(65.57 \%)$ & l & $64(63.37 \%)$ & l & $16(76.19 \%)$ & l & $24(42.86 \%)$ \\
\hline Age [years] & $67.42 \pm 10.65$ & 0.117 & $68.13 \pm 10.16$ & 0.053 & $64.00 \pm 12.45$ & 0.768 & $64.89 \pm 9.53$ \\
\hline Weight [kg] & $64.65 \pm 9.37$ & $<0.001$ & $64.46 \pm 9.80$ & $<0.001$ & $65.57 \pm 7.07$ & $<0.001$ & $61.77 \pm 8.43$ \\
\hline BMI $\left[\mathrm{kg} / \mathrm{m}^{2}\right]$ & $23.24 \pm 2.42$ & $<0.001$ & $23.29 \pm 2.56$ & $<0.001$ & $23.04 \pm 1.63$ & $<0.001$ & $23.08 \pm 2.27$ \\
\hline $\mathrm{SBP}[\mathrm{mm} \mathrm{Hg}]$ & $142.56 \pm 101.18$ & 0.927 & $147.41 \pm 110.35$ & 0.701 & $119.24 \pm 18.73$ & $<0.001$ & $141.68 \pm 19.31$ \\
\hline $\mathrm{DBP}[\mathrm{mm} \mathrm{Hg}]$ & $76.99 \pm 11.15$ & 0.482 & $76.28 \pm 10.57$ & 0.267 & $80.43 \pm 13.36$ & 0.556 & $78.41 \pm 12.99$ \\
\hline Pulse & $76.29 \pm 13.22$ & 0.848 & $76.11 \pm 12.91$ & 0.910 & $77.14 \pm 14.95$ & 0.735 & $75.86 \pm 14.19$ \\
\hline Hypertension, $n(\%)$ & $84(68.85 \%)$ & I & 70 (69.31\%) & I & $14(66.67 \%)$ & I & 36 (64.29\%) \\
\hline $\begin{array}{l}\text { Diabetes mellitus, } \\
n(\%)\end{array}$ & $25(20.49 \%)$ & / & $21(20.79 \%)$ & / & $4(19.05 \%)$ & / & $9(16.07 \%)$ \\
\hline Dyslipidemia, $n$ (\%) & 35 (28.69\%) & I & $29(28.71 \%)$ & 1 & $6(28.57 \%)$ & 1 & 15 (26.79\%) \\
\hline $\begin{array}{l}\text { Current smoking, } \\
n(\%)\end{array}$ & 28 (22.95\%) & I & 21 (20.79\%) & I & $7(33.33 \%)$ & I & $10(30.36 \%)$ \\
\hline Family history, $n$ (\%) & $21(17.21 \%)$ & I & $16(15.84 \%)$ & I & $5(23.81 \%)$ & I & $2(3.57 \%)$ \\
\hline ACE-I or ARB, $n(\%)$ & $33(27.05 \%)$ & / & 27 (26.73\%) & / & $6(28.57 \%)$ & / & $7(12.5 \%)$ \\
\hline Statins, $n(\%)$ & $10(8.20 \%)$ & I & $8(7.92 \%)$ & I & $2(9.52 \%)$ & l & $0(0 \%)$ \\
\hline$\beta$-blockers, $n(\%)$ & $9(7.38 \%)$ & 1 & $8(7.92 \%)$ & 1 & $1(4.76 \%)$ & / & $2(3.57 \%)$ \\
\hline Aspirin, $n(\%)$ & $11(9.02 \%)$ & / & $9(8.91 \%)$ & I & $2(9.52 \%)$ & / & $0(0 \%)$ \\
\hline LVSF (\%) & $38.06 \pm 8.16$ & 0.672 & $38.86 \pm 7.85$ & 0.780 & $34.19 \pm 8.75$ & 0.047 & $38.54 \pm 6.40$ \\
\hline LVEF (\%) & $66.10 \pm 10.76$ & 0.199 & $67.62 \pm 9.98$ & 0.699 & $58.80 \pm 11.57$ & 0.002 & $68.21 \pm 8.59$ \\
\hline LVIDd [cm] & $4.93 \pm 0.53$ & 0.017 & $4.92 \pm 0.52$ & 0.027 & $4.98 \pm 0.57$ & 0.096 & $4.74 \pm 0.49$ \\
\hline LVIDs [cm] & $3.12 \pm 0.60$ & 0.021 & $3.07 \pm 0.59$ & 0.089 & $3.35 \pm 0.58^{\wedge}$ & 0.005 & $2.92 \pm 0.50$ \\
\hline$L A[\mathrm{~cm}]$ & $3.91 \pm 0.58$ & 0.046 & $3.92 \pm 0.60$ & 0.045 & $3.86 \pm 0.46$ & 0.266 & $3.72 \pm 0.59$ \\
\hline TG $[\mathrm{mmol} / \mathrm{l}]$ & $1.59 \pm 0.77$ & 0.005 & $1.54 \pm 0.69$ & 0.015 & $1.87 \pm 1.03$ & 0.001 & $1.28 \pm 0.49$ \\
\hline $\mathrm{TC}[\mathrm{mmol} / \mathrm{l}]$ & $4.33 \pm 1.06$ & 0.001 & $4.29 \pm 1.03$ & 0.001 & $4.53 \pm 1.17$ & 0.002 & $3.77 \pm 0.84$ \\
\hline $\mathrm{HDL}-\mathrm{c}[\mathrm{mmol} / \mathrm{l}]$ & $1.12 \pm 0.26$ & $<0.001$ & $1.13 \pm 0.25$ & 0.001 & $1.06 \pm 0.29$ & 0.001 & $1.38 \pm 0.29$ \\
\hline LDL-c [mmol/l] & $2.43 \pm 0.73$ & $<0.001$ & $2.42 \pm 0.73$ & $<0.001$ & $2.50 \pm 0.70$ & 0.001 & $1.94 \pm 0.61$ \\
\hline $\mathrm{SCr}[\mu \mathrm{mol} / \mathrm{l}]$ & $80.89 \pm 18.35$ & 0.006 & $80.10 \pm 17.80$ & 0.018 & $84.67 \pm 20.84$ & 0.012 & $73.79 \pm 14.56$ \\
\hline $\begin{array}{l}\text { eGFR } \\
{\left[\mathrm{ml} / \mathrm{min} / 1.73 \mathrm{~m}^{2}\right]}\end{array}$ & $78.20 \pm 15.67$ & 0.239 & $78.19 \pm 15.37$ & 0.249 & $78.26 \pm 17.43$ & 0.506 & $81.16 \pm 15.37$ \\
\hline $\mathrm{FBG}[\mathrm{mmol} / \mathrm{l}]$ & $5.94 \pm 2.00$ & 0.376 & $5.67 \pm 1.30$ & 0.960 & $7.25 \pm 3.68$ & 0.013 & $5.68 \pm 1.70$ \\
\hline $\mathrm{HbA}_{1 \mathrm{c}}(\%)$ & $5.99 \pm 1.07$ & 0.166 & $5.89 \pm 0.92$ & 0.415 & $6.46 \pm 1.53$ & 0.062 & $5.76 \pm 1.00$ \\
\hline Hemoglobin $[\mathrm{g} / \mathrm{l}]$ & $132.94 \pm 20.66$ & 0.514 & $133.54 \pm 21.31$ & 0.673 & $130.05 \pm 17.40$ & 0.261 & $134.80 \pm 16.02$ \\
\hline Fibrinogen $[\mathrm{g} / \mathrm{l}]$ & $2.77 \pm 0.81$ & 0.383 & $2.68 \pm 0.72$ & 0.972 & $3.23 \pm 1.07$ & 0.035 & $2.68 \pm 0.56$ \\
\hline $\mathrm{hsCRP}[\mathrm{mg} / \mathrm{l}]$ & $9.67 \pm 14.16$ & 0.004 & $6.71 \pm 6.28$ & 0.003 & $23.90 \pm 27.56$ & $<0.001$ & $4.11 \pm 2.21$ \\
\hline \multicolumn{8}{|c|}{ Number of coronary arteries narrowed, $n(\%)$ : } \\
\hline 1-vessel disease & $50(40.98 \%)$ & I & $45(44.55 \%)$ & I & $5(23.81 \%)$ & I & 0 \\
\hline 2-vessel disease & $32(26.23 \%)$ & / & $30(29.70 \%)$ & / & $2(9.52 \%)$ & / & 0 \\
\hline 3-vessel disease & $40(32.79 \%)$ & / & $26(25.74 \%)$ & / & $14(66.67 \%)$ & / & 0 \\
\hline Nogo-A [ng/ml] & $6.95 \pm 3.66$ & $<0.001$ & $6.93 \pm 3.72$ & $<0.001$ & $7.05 \pm 3.43$ & 0.001 & $4.16 \pm 2.48$ \\
\hline $\mathrm{ROS}[\mathrm{IU} / \mathrm{ml}]$ & $991.82 \pm 773.38$ & $<0.001$ & $936.42 \pm 790.35$ & 0.003 & $1258.25 \pm 636.66$ & $<0.001$ & $580.64 \pm 369.87$ \\
\hline
\end{tabular}

All values are mean $\pm S D$; a,b same letters indicate no statistical significance based on Tukey's HSD post-hoc test or Wilcoxon's rank-sum test. ACS - acute coronary syndrome, UAP - unstable angina pectoris, AMI - acute myocardial infarction, BMI - body mass index, SBP systolic blood pressure, DBP - diastolic blood pressure, ACE-I - angiotensin-converting enzyme inhibitor, ARB - angiotensin receptor blocker, LVSF - left ventricular shortening fraction, LVEF - left ventricular ejection fraction, LVIDd - left ventricular internal diastolic diameter, LVIDs left ventricular internal dimension systole at end-diastole, $L A$ - left atrium, TG - triglyceride, TC - total cholesterol, HDL-c - HDL cholesterol, $L D L-c-L D L$ cholesterol, $S C r$ - serum creatinine, eGFR - estimated glomerular filtration rate, FBG - fasting blood glucose. 
sensitivity and $78.6 \%$ specificity; 4) ROS could not improve the predictive values of CHD.

Reactive oxygen species and antioxidants are in equilibrium in the human body. The disturbance of this equilibrium by the increase of ROS or decrease of antioxidant capacity causes oxidative stress. It is widely accepted that the occurrence of oxidative stress promotes CHD and increases plaque vulnerability [20]. Reactive oxygen species are continuously generated in the body as a consequence of aerobic metabolism or as part of the body's defense against microorganisms. Overproduction of ROS will consequently increase mitochondrial permeability transition, decrease mitochondrial membrane potential, release pro-apoptotic factors, and lead to activation of caspase-3 and apoptosis [21, 22]. Protection of mitochondrial function is therefore a promising therapeutic strategy for the treatment of CHD.

To the best of our knowledge, this is the first report to demonstrate the relationship between Nogo-A expression and CHD. Nogo-A is generally considered to be the most important inhibitor of axonal growth in models of CNS [23]. In addition to its significant role in neuronal regeneration in the CNS, Nogo-A is reported to be involved in glucose homeostasis. Nogo-A knockout mice present increased insulin secretion, resulting in higher glucose clearance [24]. Moreover, knockdown of Nogo-A specifically inhibits the growth of hepatocellular carcinoma SMMC-7721 cell line [25]. Nevertheless, little is known regarding the role of Nogo-A expression in CHD. Molecular and biochemical analysis has demonstrated that Nogo-A is expressed in adult human heart [26], and increasing evidence has shown that Nogo may serve as a novel indicator of heart failure [14]. Moreover, amino-Nogo-A, a long specific region (amino acids 186-1004) of Nogo-A, showed a strong cytoprotective effect against $\mathrm{H}_{2} \mathrm{O}_{2}$-induced oxidative stress in vitro [7]. Taken together with these results, we hypothesize that Nogo-A may affect ROS production, and subsequently induce the oxidative stress that was responsible for CHD. Thus, it drove us to analyze the association between Nogo-A, ROS and CHD.

The present study was designed to evaluate the association of Nogo-A and ROS with CHD and also investigate the relationships between plasma Nogo-A and the risk of CHD. Since this is the first study to assess the role of Nogo-A expression in CHD, we believe that Nogo-A may be used as a potential biomarker for clinical and molecular diagnosis of CHD, with a threshold of $5.466 \mathrm{ng} / \mathrm{ml}$ for diagnostic performance (59\% sensitivity and $78.6 \%$ specificity), whereas Nogo-B has a threshold of $821.96 \mathrm{pg} / \mathrm{ml}$ for maximized diagnostic

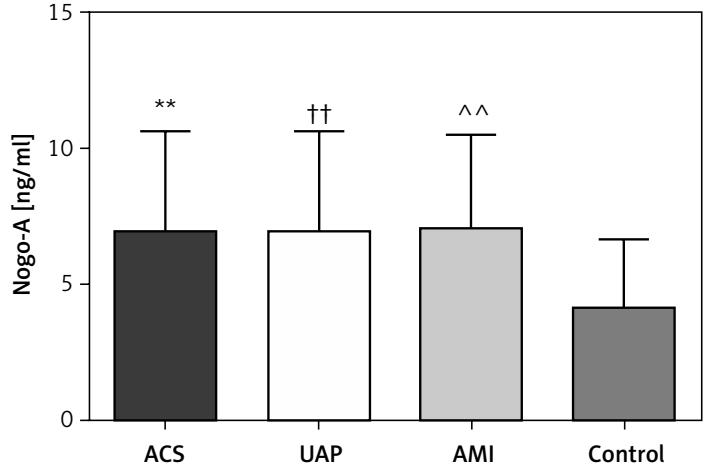

Figure 1. Nogo-A concentrations in ACS, UAP, AMI control subjects

${ }^{* *} p<0.001$, for ACS group compared with controls,

${ }^{+1} p<0.001$, for UAP group compared with controls,

$\wedge \wedge p=0.001$, for AMI group compared with controls.

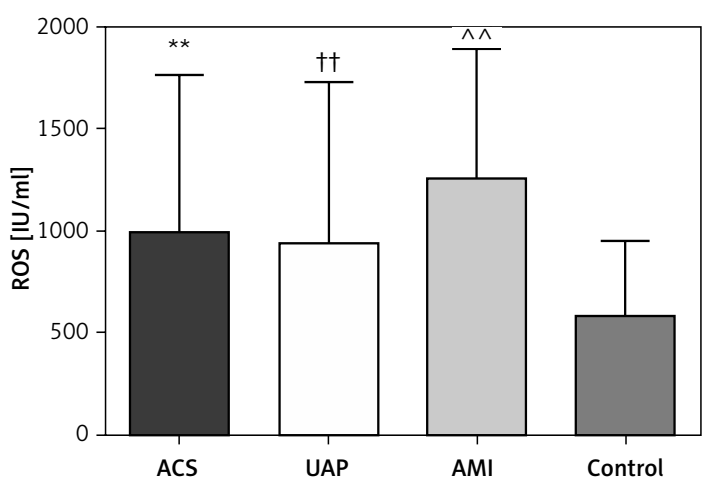

Figure 2. ROS concentrations in ACS, UAP, AMI and control subjects

${ }^{* *} P<0.001$, for ACS group compared with controls,

${ }^{+1} p=0.002$, for UAP group compared with controls,

$\wedge \wedge p<0.001$, for AMI group compared with controls.

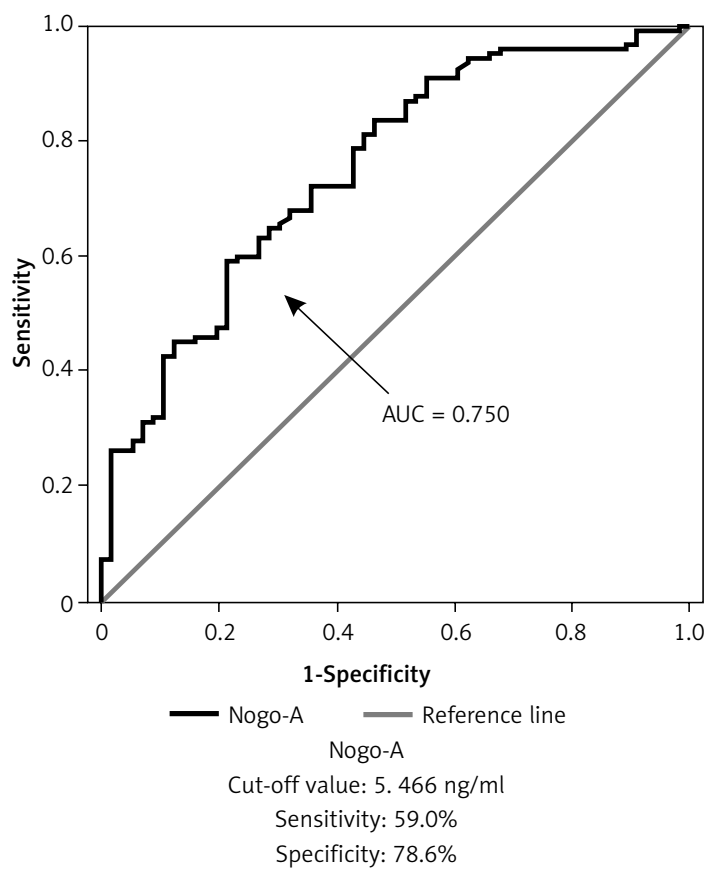

Figure 3. ROC curve analysis of the diagnostic value of plasma Nogo-A for CHD 
Table II. Univariate and multivariate logistic regression model for prediction of CHD

\begin{tabular}{|c|c|c|c|c|}
\hline Parameter & $\begin{array}{c}\text { Univariate analysis OR } \\
(95 \% \mathrm{Cl})\end{array}$ & $P$-value & $\begin{array}{c}\text { Multivariate analysis OR } \\
(95 \% \mathrm{Cl})\end{array}$ & $P$-value \\
\hline Age [years] & $1.024(0.993-1.056)$ & 0.132 & Not selected & \\
\hline BMI $\left[\mathrm{kg} / \mathrm{m}^{2}\right]$ & $1.735(1.419-2.121)$ & $<0.001$ & $1.666(1.294-2.145)$ & 0.001 \\
\hline $\mathrm{SBP}[\mathrm{mm} \mathrm{Hg}]$ & $1.000(0.996-1.004)$ & 0.948 & Not selected & \\
\hline $\mathrm{HbA}_{1 \mathrm{c}}(\%)$ & $1.275(0.894-1.819)$ & 0.179 & Not selected & \\
\hline $\mathrm{eGFR}\left[\mathrm{ml} / \mathrm{min} / 1.73 \mathrm{~m}^{2}\right]$ & $0.988(0.967-1.008)$ & 0.240 & $0.983(0.955-1.012)$ & 0.241 \\
\hline $\mathrm{FBG}[\mathrm{mmol} / \mathrm{l}]$ & $1.088(0.890-1.330)$ & 0.409 & $1.163(0.886-1.527)$ & 0.276 \\
\hline TG $[\mathrm{mmol} / \mathrm{l}]$ & $2.207(1.238-3.932)$ & 0.007 & Not selected & \\
\hline $\mathrm{TC}[\mathrm{mmol} / \mathrm{l}]$ & $1.837(1.284-2.629)$ & 0.001 & $1.496(0.851-2.627)$ & 0.162 \\
\hline $\mathrm{HDL}-\mathrm{c}[\mathrm{mmol} / \mathrm{l}]$ & $0.033(0.009-0.121)$ & $<0.001$ & Not selected & \\
\hline LDL-c [mmol/l] & $3.022(1.759-5.189)$ & $<0.001$ & $3.544(1.420-8.848)$ & 0.007 \\
\hline hsCRP $[\mathrm{mg} / \mathrm{l}]$ & $1.178(1.059-1.311)$ & 0.003 & $1.225(1.046-1.436)$ & 0.012 \\
\hline Fibrinogen $[\mathrm{g} / \mathrm{l}]$ & $1.190(0.762-1.860)$ & 0.444 & Not selected & \\
\hline Nogo-A [ng/ml] & $1.414(1.217-1.643)$ & $<0.001$ & $1.624(1.125-2.293)$ & 0.009 \\
\hline $\mathrm{ROS}[\mathrm{IU} / \mathrm{ml}]$ & $1.001(1.001-1.002)$ & 0.001 & $0.999(0.997-1.001)$ & 0.320 \\
\hline
\end{tabular}

$B M I$ - body mass index, SBP - systolic blood pressure, eGFR - estimated glomerular filtration rate, FBG - fasting glucose, TG - triglyceride, $T C$ - total cholesterol, HDL-c - HDL cholesterol, LDL-c - LDL cholesterol.

performance of ACS (42.2\% sensitivity and $96.4 \%$ specificity). It seems that the combination examination of Nogo-A and Nogo-B may improve the diagnostic efficiency and accuracy for CHD.

The main limitation of this study is the relatively small population because of our exclusion criteria, and the lack of clinical follow-up with these subjects. Further studies with a larger sample size need to be performed.

\section{Acknowledgments}

This work was supported by grants from Beijing LS Cardiovascular Health Foundation (no. LSG151132), Nature Science Foundation of Zhejiang Province (no. Y15H020003), Hangzhou Bureau of Science and Technology (no. 20120533Q03 and 20150633B16) and the Ministry of Public Health of Zhejiang Province (no. 2013KYA158).

\section{Conflict of interest}

The authors declare no conflict of interest.

\section{References}

1. Go AS, Mozaffarian D, Roger VL, et al. American Heart Association Statistics Committee and Stroke Statistics Subcommittee. Heart disease and stroke statistics 2013 update: a report from the American Heart Association. Circulation 2013; 127: e6-245.

2. Koyama K, Yoneyama K, Mitarai T, et al. Association between inflammatory biomarkers and thin-cap fibroatheroma detected by optical coherence tomography in patients with coronary heart disease. Arch Med Sci 2015; 11: 505-12.

3. Ikonomidis I, Makavos G, Papadavid E, et al. Similarities in coronary function and myocardial deformation between psoriasis and coronary artery disease: the role of oxidative stress and inflammation. Can J Cardiol 2015; 31: 287-95.

4. Prasad K, Dhar I. Oxidative stress as a mechanism of added sugar-induced cardiovascular disease. Int J Angiol 2014; 23: 217-26.

5. Tullio F, Angotti C, Perrelli MG, Penna C, Pagliaro P. Redox balance and cardioprotection. Basic Res Cardiol 2013; 108: 392.

6. Zhang C, Yu H, Shen Y, Ni X, Shen S, Das UN. Polyunsaturated fatty acids trigger apoptosis of colon cancer cells through a mitochondrial pathway. Arch Med Sci 2015; 11: 1081-94.

7. Kertmen H, Gürer B, Yilmaz ER, et al. Antioxidant and antiapoptotic effects of darbepoetin-alpha against traumatic brain injury in rats. Arch Med Sci 2015; 11 : 1119-28.

8. Mi YJ, Hou B, Liao QM, et al. Amino-Nogo-A antagonizes reactive oxygen species generation and protects immature primary cortical neurons from oxidative toxicity. Cell Death Differ 2012; 19: 1175-86.

9. Chen MS, Huber AB, van der Haar ME, et al. Nogo-A is a myelin-associated neurite outgrowth inhibitor and an antigen for monoclonal antibody IN-1. Nature 2000; 403: 434-9.

10. Papadopoulos CM, Tsai SY, Alsbiei T, O’Brien TE, Schwab ME, Kartje GL. Functional recovery and neuroanatomical plasticity following middle cerebral artery occlusion and IN-1 antibody treatment in the adult rat. Ann Neurol 2002; 51: 433-41.

11. Hu WH, Hausmann ON, Yan MS, Walters WM, Wong PK, Bethea JR. Identification and characterization of a novel 
Nogo-interacting mitochondrial protein (NIMP). J Neurochem 2002; 81: 36-45.

12. Nath AK, Krauthammer M, Li P, et al. Proteomic-based detection of a protein cluster dysregulated during cardiovascular development identifies biomarkers of congenital heart defects. PLoS One 2009; 4: e4221.

13. Sarkey JP, Chu M, McShane M, et al. Nogo-A knockdown inhibits hypoxia/reoxygenation-induced activation of mitochondrial-dependent apoptosis in cardiomyocytes. J Mol Cell Cardiol 2011; 50: 1044-55.

14. Bullard TA, Protack TL, Aguilar F, Bagwe S, Massey HT, Blaxall BC. Identification of Nogo as a novel indicator of heart failure. Physiol Genomics 2008; 32: 182-9.

15. Gao B, Xu Y, Leng J, Wang K, Xia B, Huang J. Clinical implications of increased Nogo-B levels in patients with acute coronary syndromes and stable angina pectoris. Int Heart J 2015; 56: 341-4.

16. Judkins MP. Percutaneous transfemoral selective coronary arteriography. Radiol Clin North Am 1968; 6: 467-92.

17. Milner KA, Funk M, Richards S, Vaccarino V, Krumholz HM. Symptom predictors of acute coronary syndrome in younger and older patients. Nurs Res 2001; 50: 233-41.

18. Braunwald E, Antman EM, Beasley JW, et al.; American College of Cardiology/American Heart Association Task Force on Practice Guidelines (Committee on the Management of Patients With Unstable Angina). ACC/AHA guideline update for the management of patients with unstable angina and non-ST-segment elevation myocardial infarction-2002: summary article: a report of the American College of Cardiology/American Heart Association Task Force on Practice Guidelines (Committee on the Management of Patients With Unstable Angina). Circulation 2002; 106: 1893-900.

19. Thygesen K, Alpert JS, White HD; Joint ESC/ACCF/AHA/ WHF Task Force for the Redefinition of Myocardial Infarction. Universal definition of myocardial infarction. J Am Coll Cardiol 2007; 50: 2173-95.

20. Dzau VJ, Antman EM, Black HR, et al. The cardiovascular disease continuum validated: clinical evidence of improved patient outcomes. Part I: Pathophysiology and clinical trial evidence (risk factors through stable coronary artery disease). Circulation 2006; 114: 2850-70.

21. Danial NN, Korsmeyer SJ. Cell death: critical control points. Cell 2004; 116: 205-19.

22. Tsujimoto $\mathrm{Y}$, Nakagawa T, Shimizu S. Mitochondrial membrane permeability transition and cell death. Biochim Biophys Acta 2006; 1757: 1297-300.

23. Horner PJ, Gage FH. Regenerating the damaged central nervous system. Nature 2000; 407: 963-70.

24. Bonal CB, Baronnier DE, Pot C, et al. Nogo-A downregulation improves insulin secretion in mice. Diabetes 2013; 62: 1443-52.

25. Hao CQ, Zhou Y, Wang JP, et al. Role of Nogo-A in the regulation of hepatocellular carcinoma SMMC-7721 cell apoptosis. Mol Med Rep 2014; 9: 1743-8.

26. Huber AB, Weinmann O, Brosamle C, Oertle T, Schwab ME. Patterns of Nogo mRNA and protein expression in the developing and adult rat and after CNS lesions. J Neurosci 2002; 22: 3553-67. 